\title{
Impact of a Novel Training Approach on Body Composition in the Elderly
}

\author{
Matthew C Scott ${ }^{1}$, Jason D. Allen ${ }^{2,3}$, Neil M. Johannsen ${ }^{1,4}$, Daniel P. Credeur ${ }^{5}$, Conrad P. Earnest ${ }^{6}$, \\ Timothy S. Church ${ }^{4}$, Eric Ravussin ${ }^{4}$, William E. Kraus ${ }^{3}$ and Michael A. Welsch ${ }^{7 *}$
}

${ }^{1}$ School of Kinesiology, Louisiana State University, USA

${ }^{2}$ Department of Kinesiology, University of Virginia, USA

${ }^{3}$ Duke Molecular Physiology Institute, Duke University School of Medicine, USA

${ }^{4}$ Pennington Biomedical Research Center, USA

${ }^{5}$ School of Kinesiology and Nutrition, University of Southern Mississippi, USA

${ }^{6}$ Department of Health and Kinesiology, Texas A\&M University, USA

${ }^{7}$ School of Population Health, University of Mississippi Medical Center, USA

*Corresponding author: Michael Andrew Welsch, Ph.D., FACSM, Professor of Population Health Science, The John D. Bower School of Population Health, University of Mississippi Medical Center, 2500 N. State St. Jackson, MS 39216, USA, Tel: (601)-815-9553

\begin{abstract}
Background/Purpose: Deterioration of body composition with advancing age is related to functional decline. This study examined the effects of a novel progressive exercise training program on body composition in individuals $>70 \mathrm{y}$, at risk of losing functional independence.

Methods: Fifty participants (33 females, $75 \pm 4.5$ y) performed $45-60$ min sessions, 3 times per week, for a total of 12 weeks. Training consisted of 2 distinct phases. For Phase I (First 4 weeks) participants were randomized to aerobic training consisting of walking or cycling at $50 \%$ of heart rate reserve, or PRIME (Peripheral Remodeling through Intermittent Muscular Exercise) designed to stimulate the major muscle groups (8 targeted exercises) at $40 \%-50 \%$ of maximal voluntary capacity, for a duration of 3-6 min, or 45 to 90 contractions. Phase I was followed by 8 weeks of combined aerobic and resistance training using established exercise guidelines (phase II). Body composition (Fat Free Mass, Fat Mass, body fat \%, Skeletal Muscle Index, bone mineral content and density) were measured using Dual X-ray Absorptiometry, before (V1), and after Phase I (V2) and II (V3).
\end{abstract}

Results: Compared to V1, V3 values for Body Fat $\%$ ( $p=$ $0.005)$ decreased, and Fat Free Mass $(p=0.03)$ and Skeletal Muscle Index $(p=0.05)$ increased, in both groups. Changes
Changes in Bone Mineral Content and Bone Mineral Density were significantly greater for PRIME compared to the aerobically trained group $(p<0.05)$.

Conclusion: Both groups improved body fat percentage, increased SMI, and BMC and BMD, in specific sites measured. Uniquely, participants whom initiated training with PRIME experienced greater improvements in BMC and BMD. These data support a paradigm shift in the order of exercise training, for older adults at risk of losing independence, with initial emphasis on a moderate to high intensity localized exercise stimulus, rather than moderate to high intensity systemic exercise.

\section{Keywords}

Exercise, Skeletal muscle index, Bone mineral density, Aging

\section{Introduction}

Aging is associated with significant changes in body composition. Evidence from the Baltimore Longitudinal Aging Study (BLAS) demonstrates Fat Free Mass (FFM) increases up to the $3^{\text {rd }}$ decade of life, after which it remains relatively stable until an accelerated decline, starting at age of 50 for men and 60 for women [1]. 
Body fat increases until $\sim 65$ years [2] and redistributes to the abdominal area and visceral organs [3]. The lifetime apex for bone mass (i.e., peak bone mass) occurs in early adulthood [4]. Then, from the $4^{\text {th }}$ to the end of the $8^{\text {th }}$ decade, men and women lose $19 \%$ and $39 \%$ trabecular BMD, respectively [5]. Collectively body compensation changes contribute to reduced cardiorespiratory capacity [1], and increased risk for cardio-metabolic disease [6,7], sarcopenia [8], osteopenia [9], and frailty [10]. Importantly, physical inactivity exacerbates the age-dependent changes in body composition [11]. As the proportion of people worldwide above $65 \mathrm{yr}$ continues to grow to $16 \%$ by 2050 [12], and physical inactivity remains a global problem [11], the prevalence of these conditions will rise, requiring innovative strategies to reduce the socio-economic challenges associated with aging.

Exercise training is recognized as an effective countermeasure to changes in body composition with advancing age [13]; however, optimal exercise training strategies and/or dosing are not fully known. We have previously reported that participants in the Peripheral Remodeling through Intermittent Muscular Exercise (PRIME) trial [14] experienced greater increases in cardiorespiratory and muscular fitness and physical function when a combination of aerobic (AT) and Resistance Training (RT), was preceded by 4 weeks of moderate to high intensity localized muscular exercise (PRIME), compared to moderate to high intensity systemic exercise (AT). The rationale for PRIME was based on: (1) Evidence from the BLAS that accelerated decline in $\mathrm{VO}_{2}$ Peak after $65 \mathrm{y}$ is primarily due to reduced peripheral blood flow, skeletal muscle mass and metabolism [1]; and (2) The prevalence of systemic limitations preventing many elderly to achieve an adequate intensity of exercise to stimulate the peripheral barriers [15].

The purpose of the study was: (1) To examine the effects of 12 weeks of exercise training on body composition, including (body weight, Fat and FFM, Bone Mineral Content (BMC), and Bone Mineral Density (BMD)), in elderly at risk for losing functional independence, and (2) To determine if preceding AT/RT, by 4 weeks of PRIME or AT, would contribute to differential body composition responses. It was hypothesized that 12 weeks of exercise training would improve body composition in elderly at risk for losing functional independence, and that the improvements would be greater in those randomized to PRIME compared to AT during the initial 4 weeks of training.

\section{Methods}

\section{Recruitment strategy}

The goal was to enroll participants over the age of 70 , and at risk for losing functional independence based on a peak cardiorespiratory capacity ( $\mathrm{VO}_{2}$ peak) of $15-20$ $\mathrm{mL} / \mathrm{kg} / \mathrm{min}$. This range has been shown to be associat- ed with a threshold for loss of functional independence [16]. The recruitment process involved phone screen interviews to determine participant eligibility. Qualifying participants then attended an orientation visit, including an explanation of study procedures, signing of an informed consent, a review of medical history, and a 6 -min walk test [17]. Using previous data from the Louisiana Healthy Aging Study ( $n=286$, unpublished), subjects who walked between 200 and $450 \mathrm{~m}$ in a standard 6-min walk test had a $\mathrm{VO}_{2}$ peak of approximately 15-20 $\mathrm{ml} / \mathrm{kg} / \mathrm{min}$ and could proceed to the baseline testing visits.

\section{Study design}

The current report is a 2-arm, prospective pilot randomized trial with participants assigned, to 4 weeks of standard PRIME or AT (Phase I, detailed below). This was followed by 8 weeks of progressive whole-body AT/ RT by all participants (Phase II). All individuals gave their informed consent prior to inclusion in the study. The study was conducted at the Pennington Biomedical Research Center, Baton Rouge, LA. The research protocol was reviewed and approved annually by the institutional ethics committee.

\section{Participants}

Individuals over the age of 70 , and who walked between 200 to $450 \mathrm{~m}$ on a 6-min walk test were eligible for participation. Specific exclusion criteria included any unstable or uncontrolled medical conditions. If a volunteer was eligible, they initiated baseline testing (V1) followed by randomization to one of two groups (a) 4 weeks of PRIME or (b) 4 weeks of AT (Phase I). After completion of Phase I, participants completed an intermediate testing assessment (V2), followed by Phase II, which consisted of 8 weeks of a AT/RT based on published physical activity guidelines for older adults $[13,18,19]$. After phase II, participants completed a final follow-up visit (V3). Both follow-up visits were performed within 5 $\mathrm{d}$ of the final Phase I and II training sessions, to minimize any detraining effects. All testing procedures between Phase I and II were completed in less than $7 \mathrm{~d}$.

\section{Exercise interventions}

All training sessions lasted 45-60 min, including warm-up, training, and cooldown, and were conducted three times per week for a total of $12 \mathrm{wk}$. Participants assigned to PRIME, during Phase I, performed eight exercises (see Table 1). Each exercise involved contractions at a moderate load, defined as $40 \%-50 \%$ of maximal voluntary capacity, for a duration of up to $6 \mathrm{~min}$. Participants assigned to AT during Phase I performed whole-body aerobic exercise at $50 \%$ of Heart Rate Reserve (HRR) on an Airdyne cycle ergometer (Nautilus, Inc., Vancouver, WA) using both arms and legs for 20 minutes (including a 5-minute warm-up) and then walked on a treadmill for 25 minutes (including a 5-minute cooldown). 
Table 1: PRIME exercise protocol.

\begin{tabular}{|l|l|l|l|l|l|l|}
\hline Exercise & d/wk & $\begin{array}{l}\text { Duration } \\
\text { (min) }\end{array}$ & Starting Int & Progression & Cadence & Comments \\
\hline Calf Raises & 3 & 5 & Body Weight & $8 \%-10 \%$ of body weight & $1 / 4 \mathrm{sec}$ & Both legs \\
\hline Handgrip & 3 & 5 & $50 \%$ MVC & $8 \%-10 \%$ of previous load & $1 / 4 \mathrm{sec}$ & Alternating hands \\
\hline Leg Press & 3 & 6 & $40-50 \%$ MVC & $8 \%-10 \%$ of previous load & $1 / 4 \mathrm{sec}$ & Both legs \\
\hline Seated Row & 3 & 5 & $40-50 \%$ MVC & $8 \%-10 \%$ of previous load & $1 / 4 \mathrm{sec}$ & Both arms \\
\hline Chest Press & 3 & 5 & $40-50 \%$ MVC & $8 \%-10 \%$ of previous load & $1 / 4 \mathrm{sec}$ & Both arms \\
\hline Modified Squat & 3 & 5 & Body Weight & $8 \%-10 \%$ of previous load & $1 / 4$ sec & Use of chair or exercise ball \\
\hline Low Back & 3 & 3 & As Tolerated & $8 \%-10 \%$ of previous load & $1 / 4$ sec & Crossed arms \\
\hline Abdomen & 3 & 3 & As Tolerated & $8 \%-10 \%$ of previous load & $1 / 4$ sec & $\begin{array}{l}\text { Pads on movement arm on } \\
\text { chest }\end{array}$ \\
\hline
\end{tabular}

Abbreviations: $\mathrm{d} / \mathrm{wk}=$ days per week; Int = Intensity; $\mathrm{MVC}=$ Maximal Voluntary Contraction

Volume for each exercise was calculated by multiplying weight lifted by the number of repetitions and calculated as volume per exercise, and total volume lifted per session. Heart rate responses to exercise were monitored via Polar heart rate monitors (RS 400; Polar, Kampele, Finland) and data were analyzed for time spent in the prescribed training range and average heart rate achieved during each session. Total energy expenditure was estimated using published metabolic equations [20]. Participants were progressed, as tolerated, over subsequent sessions.

Phase II consisted of 8 weeks of combined AT/RT using established guidelines $[13,18,19]$. Participants performed 40 minutes of AT (cycle ergometer and treadmill), and one set of 10-15 repetitions using 8 RT exercises. Participants were encouraged to work at $60 \%-85 \%$ of HRR. RT load was increased by $10 \%$ for the next session, if the participant could perform the 15th lift of the set. Static stretches were performed after each exercise.

\section{Body composition measurements}

Body composition was measured by Dual X-ray Absorptiometry (DXA, QDR 4500A, Hologic Inc., Bedford, MA). Whole body scans were analyzed for Fat Mass, FFM, BMC, and BMD. Whole body scans were regionalized into head, left arm, right arm, left ribs, right ribs, thoracic spine, lumbar spine, pelvis, left leg, and right leg components using established analysis lines and reference points [21].

Additional variables calculated from the raw DXA scores included: (1) Skeletal Muscle Mass Index (SMI), defined by the sum of Appendicular Skeletal Muscle (AMS) divided by height [2,22]; and (2) the sum of the BMC (BMCcore) and BMD scores (BMDcore) calculated from the content and density values of the ribs, thoracic and lumbar spine, and the pelvis.

\section{Statistical analysis}

Statistical analyses were performed using IBM SPSS Statistics Version 24 (IBM, Inc., Armonk, NY). Data are presented as mean (SD) or mean change and $95 \%$ confi- dence intervals, where appropriate. Baseline and demographic data were examined for group differences using t-tests. To address the main hypothesis, the change scores from baseline (V1) to $12 \mathrm{wk}$ (V3) for the primary end points were analyzed. Then, data were analyzed by a repeated measure mixed model, assessing the change after each phase, controlling for the baseline of the outcome under study. Each model assessed group by time interactions, and the main effect.

\section{Results}

\section{Participant characteristics}

Fifty adults ( 27 females, $75 \pm 4.5$ y) were included in this analysis. Baseline data are presented for both PRIME and AT in Table 2. The most common medical diagnoses for participants were: Hypertension (51\%), Hypothyroidism (32\%), Osteoarthritis (28\%), Peripheral Neuropathy (23\%), Cancer (16\%), and Cardiovascular Disease (15\%). The most common medications included anti-hypertensives, and Lipid and thyroid drugs. Medical diagnoses and medications were equally distributed between groups.

\section{Training volume}

Bi-weekly exercise data are presented in Table 3. The data include average intensity during each session, progression across the study for volume lifted, and estimated energy expenditure (Phase I AT only). The intensity of training for PRIME during Phase I ranged from $41.2 \pm 21.5 \%$ to $45.8 \pm 24.3 \%$ HRR compared to $56.7 \pm 15.5 \%$ to $64.5 \pm 15.5 \%$ HRR for AT (Group comparison, $\mathrm{p}=0.01$ ).

\section{Body composition}

Body weight did not change. Body fat \% decreased in both groups $(p=0.005)$, and to a greater extent in AT (Fat \%: PRIME: $\Delta-0.47$ [95\% Cl: -0.98 to 0.04 ]; AT: $\Delta$ $-0.98 \%$ [95\% Cl: -1.44 to -0.50$], p=0.009$ ). The reduction in fat mass was greater in AT (Fat Mass: PRIME: $\Delta-483$ g [95\% Cl: -748 to 252 ]; AT: $\Delta-1039 \mathrm{~g}$ [95\% Cl: -1546 to -666], $p=0.05)$. Lean mass increased in both groups $(p=$ 0.03), (Lean Mass: PRIME: $\Delta 327 \mathrm{~g}$ [95\% Cl: -166 to 820]; 
Table 2: Study Participants Baseline (V1) Characteristics.

\begin{tabular}{|c|c|c|c|}
\hline & All $(n=50)$ & PRIME (n = 23) & AT $(n=27)$ \\
\hline Age & $75.0 \pm 4.52$ & $75.0 \pm 3.98$ & $75.0 \pm 4.97$ \\
\hline \multicolumn{4}{|l|}{ Gender } \\
\hline Female & 33 & 16 & 17 \\
\hline \multicolumn{4}{|l|}{ Resting Hemodynamics } \\
\hline Heart Rate & $67.5 \pm 8.21$ & $67.0 \pm 7.02$ & $68.5 \pm 9.31$ \\
\hline Systolic Blood Pressure & $130.8 \pm 13.23$ & $131.9 \pm 13.95$ & $130.3 \pm 12.75$ \\
\hline Diastolic Blood Pressure & $72.8 \pm 8.83$ & $73.6 \pm 10.16$ & $72.1 \pm 7.53$ \\
\hline \multicolumn{4}{|l|}{ Body Composition } \\
\hline Height & $164.58 \pm 8.54$ & $165.2 \pm 9.06$ & $163.7 \pm 8.18$ \\
\hline Weight & $80.97 \pm 16.45$ & $82.48 \pm 20.17$ & $79.7 \pm 12.48$ \\
\hline Fat Mass & $31.26 \pm 8.77$ & $29.98 \pm 7.11$ & $32.36 \pm 9.36$ \\
\hline Lean Mass & $50.43 \pm 11.46$ & $49.14 \pm 10.95$ & $51.73 \pm 11.64$ \\
\hline SMI $\left(A M S / m^{2}\right)$ & $6.44 \pm 1.59$ & $6.25 \pm 1.49$ & $6.60 \pm 1.67$ \\
\hline \multicolumn{4}{|l|}{ Bone Mineral Density } \\
\hline Arms & $0.76 \pm 0.11$ & $0.73 \pm 0.11$ & $0.77 \pm 0.11$ \\
\hline Ribs & $0.68 \pm 0.12$ & $0.67 \pm 0.10$ & $0.70 \pm 0.14$ \\
\hline Thoracic Spine & $0.97 \pm 0.16$ & $0.94 \pm 0.17$ & $1.00 \pm 0.15$ \\
\hline Lumbar Spine & $1.04 \pm 0.22$ & $1.02 \pm 0.24$ & $1.06 \pm 0.21$ \\
\hline Pelvis & $1.20 \pm 0.17$ & $1.18 \pm 0.17$ & $1.22 \pm 0.17$ \\
\hline Legs & $1.20 \pm 0.19$ & $1.18 \pm 0.20$ & $1.22 \pm 0.18$ \\
\hline
\end{tabular}

Values are means \pm SD

Table 3: Bi-weekly exercise training data.

\begin{tabular}{|l|l|l|l|l|l|l|}
\hline & \multicolumn{2}{|c|}{ Phase 1 } & \multicolumn{4}{c|}{ Phase 2 } \\
\hline & Mean \pm SD & Mean \pm SD & Mean \pm SD & Mean \pm SD & Mean \pm SD & Mean \pm SD \\
\hline PRIME & Weeks 1\&2 & Weeks 3\&4 & Weeks 5\&6 & Weeks 7\&8 & Weeks 9\&10 & Weeks 11\&12 \\
\hline Volume Lifted, Ibs & $37291 \pm 7637$ & $42143 \pm 7603$ & $10965 \pm 2917$ & $12837 \pm 3024$ & $13172 \pm 3288$ & $14305 \pm 2699$ \\
\hline Intensity, \% HRR & $41.2 \pm 21.5^{*}$ & $45.8 \pm 24.3^{*}$ & $60.0 \pm 19.2$ & $65.6 \pm 17.3$ & $70.3 \pm 16.7$ & $71.0 \pm 19.3$ \\
\hline EE, Kcal & N/A & N/A & $130 \pm 33.7$ & $162 \pm 41.0$ & $177 \pm 45.5$ & $188 \pm 47.0$ \\
\hline AT & Weeks 1\&2 & Weeks 3\&4 & Weeks 5\&6 & Weeks 7\&8 & Weeks 9\&10 & Weeks $11 \& 12$ \\
\hline Volume Lifted, Ibs & N/A & N/A & $11084 \pm 3260$ & $12867 \pm 3642$ & $14304 \pm 4061$ & $15080 \pm 4412$ \\
\hline Intensity, \% HRR & $56.7 \pm 15.5$ & $64.5 \pm 15.5$ & $62.0 \pm 19.5$ & $65.9 \pm 16.2$ & $68.3 \pm 14.5$ & $69.1 \pm 15.3$ \\
\hline EE, Kcal & $160 \pm 36.5$ & $191 \pm 39.9$ & $166 \pm 35.0$ & $183 \pm 38.5$ & $196 \pm 48.1$ & $206 \pm 52.5$ \\
\hline
\end{tabular}

Abbreviations: $S D=$ Standard Deviation, $H R R=$ Heart Rate Reserve, EE = Energy expenditure. N/A = Not Applicable.

Data presented bi-weekly with per-session ( 3 sessions per week) averages. ${ }^{*} p<0.05$, Phase I group comparison for exercise intensity

AT: $\Delta 232 \mathrm{~g}$ [95\% Cl: -350.88 to 815.24$])$. Finally, SMI increased in both groups $(p=0.05)$ from V1 to V3.

\section{Bone mineral content and bone mineral density}

Data for BMC and BMD are presented in Table 4 and Table 5. The Tables provide $p$-values for time effect, group by time interaction, and group differences for the change scores from V2 to V1, and from V3 to V1. For those in PRIME, BMC improved at the ribs, thoracic spine, and pelvis. For AT BMC decreased at the ribs, and Thoracic Spine. Change scores (V3-V1) between groups were: (1) Arms (PRIME: $-2.81 \mathrm{~g}$ [95\% Cl: -5.63 to 0.01]; AT: -2.02 g [95\% Cl: -4.62 to 0.59$], p=0.68) ;(2)$
Ribs (PRIME: $5.61 \mathrm{~g}$ [95\% Cl: 0.73 to 10.49]; AT: $-4.41 \mathrm{~g}$ [95\% Cl: -8.92 to 0.09], $p=0.004)$; (3) Thoracic Spine (PRIME: $6.31 \mathrm{~g}$ [95\% Cl: -3.11 to 15.74]; AT: $-8.92 \mathrm{~g}$ [95\% $\mathrm{Cl}:-17.62$ to -0.23$], \mathrm{p}=0.02$ ), Lumbar spine (PRIME: $2.64 \mathrm{~g}$ [95\% Cl: -1.68 to 6.96]; AT: $5.83 \mathrm{~g}$ [95\% Cl: 1.84 to 9.82], $\mathrm{p}=0.28$ ), Pelvis (PRIME: $1.72 \mathrm{~g}$ [95\% $\mathrm{Cl}:-3.68$ to 7.13]; AT: $-1.15 \mathrm{~g}$ [95\% Cl: -6.13 to 3.84], $p=0.44$ ), Legs (PRIME: $3.46 \mathrm{~g}$ [95\% Cl: -4.58 to 11.49 ]; AT: -2.67 g [95\% Cl: -10.09 to 4.74$], p=0.27)$, and for BMCcore (PRIME: 14.54 g [95\% Cl: 4.48 to 24.61]; AT: -8.28 g [95\% $\mathrm{Cl}:-17.57$ to 1.01$], \mathrm{p}=0.002)$.

BMD improved at the ribs, thoracic and lumbar spine, and pelvis, for PRIME, and AT at the pel- 
Table 4: Bone mineral content (grams) for V1, V2, and V3.

\begin{tabular}{|c|c|c|c|c|c|c|c|c|c|c|c|c|}
\hline & \multirow[t]{2}{*}{ Group } & \multirow[t]{2}{*}{ Bound } & \multicolumn{3}{|c|}{ AT } & \multicolumn{3}{|c|}{ PRIME } & \multicolumn{4}{|c|}{ p-values } \\
\hline & & & V1 & V2 & V3 & V1 & V2 & V3 & $\begin{array}{l}\text { Time } \\
\text { Effect }\end{array}$ & $\begin{array}{l}\text { Grp* } \\
\text { Time }\end{array}$ & $\begin{array}{l}\text { Grp Diff for } \\
\Delta \text { V2-V1 }\end{array}$ & $\begin{array}{l}\text { Grp Diff for } \\
\Delta \text { V3-V1 }\end{array}$ \\
\hline \multirow[t]{3}{*}{ Arms } & Mean & & 167.40a & 166.33 & 165.51 & 167.40a & 166.74 & 90.58 & 0.89 & 0.76 & 0.84 & 0.68 \\
\hline & $95 \% \mathrm{Cl}$ & LB & 167.40 & 163.25 & 162.90 & 167.40 & 163.41 & 170.08 & & & & \\
\hline & & UB & 167.40 & 169.41 & 168.20 & 167.40 & 161.61 & 167.27 & & & & \\
\hline \multirow[t]{3}{*}{ Ribs } & Mean & & $86.35 a$ & 86.66 & 82.49 & $86.35 a$ & 89.94 & 91.31 & 0.03 & 0.02 & 0.18 & 0.004 \\
\hline & $95 \% \mathrm{Cl}$ & LB & 86.35 & 82.24 & 78 & 86.35 & 85.15 & 86.45 & & & & \\
\hline & & UB & 86.35 & 91.09 & 86.97 & 86.35 & 94.74 & 96.17 & & & & \\
\hline \multirow[t]{3}{*}{ Thoracic } & Mean & & $136.94 a$ & 138.96 & 127.53 & $136.94 a$ & 141.3 & 144.03 & 0.03 & 0.01 & 0.52 & 0.02 \\
\hline & $95 \% \mathrm{Cl}$ & LB & 136.94 & 130.81 & 117.9 & 136.94 & 132.45 & 133.38 & & & & \\
\hline & & UB & 136.94 & 147.12 & 137.15 & 136.94 & 150.14 & 154.26 & & & & \\
\hline \multirow[t]{3}{*}{ Lumbar } & Mean & & $55.72 a$ & 58.32 & 62.01 & $55.72 a$ & 57.37 & 58.34 & 0.13 & 0.42 & 0.64 & 0.28 \\
\hline & $95 \% \mathrm{Cl}$ & LB & 55.72 & 53.82 & 56.67 & 55.72 & 52.42 & 51.17 & & & & \\
\hline & & UB & 55.72 & 62.82 & 67.36 & 55.72 & 62.17 & 62.75 & & & & \\
\hline \multirow[t]{3}{*}{ Pelvis } & Mean & & $225.62 a$ & 229.36 & 224.71 & $225.62 a$ & 228.28 & 229.86 & 0.26 & 0.05 & 0.02 & 0.44 \\
\hline & $95 \% \mathrm{Cl}$ & LB & 225.62 & 215.61 & 220.14 & 225.62 & 224.12 & 218.33 & & & & \\
\hline & & UB & 225.62 & 225.12 & 229.28 & 225.62 & 224.90 & 234.82 & & & & \\
\hline \multirow[t]{3}{*}{ Legs } & Mean & & $451.56 a$ & 452.39 & 448.68 & $451.56 a$ & 458.71 & 455.07 & 0.80 & 0.50 & 0.36 & 0.27 \\
\hline & $95 \% \mathrm{Cl}$ & LB & 451.56 & 443.55 & 441.34 & 451.56 & 449.12 & 446.95 & & & & \\
\hline & & UB & 451.56 & 461.24 & 456.34 & 451.56 & 510.77 & 463.19 & & & & \\
\hline \multirow[t]{3}{*}{ BMCcore } & Mean & & $505.23 a$ & 503.15 & 496.06 & $505.23 a$ & 518.79 & 520.82 & 0.16 & 0.001 & 0.02 & 0.002 \\
\hline & $95 \% \mathrm{Cl}$ & LB & 505.23 & 494.45 & 480.38 & 505.23 & 509.35 & 510.95 & & & & \\
\hline & & UB & 505.23 & 511.84 & 505.16 & 505.23 & 528.22 & 530.70 & & & & \\
\hline
\end{tabular}

Abbreviations: Grp = Group; Diff = Difference; Cl-Confidence Interval; V1 = Visit 1; V1 = Visit 1 ; V2 = Visit 2; V3 = Visit 3; $\Delta=$ Change score; LB = Lower Bound; UB = Upper Bound; BMC = Bone Mineral Content.

Table 5: Bone mineral density $\left(\mathrm{g} / \mathrm{cm}^{3}\right)$ for $\mathrm{V} 1, \mathrm{~V} 2$, and $\mathrm{V} 3$.

\begin{tabular}{|c|c|c|c|c|c|c|c|c|c|c|c|c|}
\hline & \multirow[t]{2}{*}{ Group } & & \multicolumn{3}{|c|}{ AT } & \multicolumn{3}{|c|}{ PRIME } & \multicolumn{4}{|c|}{ p-values } \\
\hline & & & V1 & V2 & V3 & V1 & V2 & V3 & $\begin{array}{l}\text { Time } \\
\text { Effect }\end{array}$ & Grp*Time & $\begin{array}{l}\text { Grp Diff for } \\
\Delta \text { V2-V1 }\end{array}$ & $\begin{array}{l}\text { Grp Diff for } \\
\Delta \text { V3-V1 }\end{array}$ \\
\hline \multirow[t]{3}{*}{ Arms } & Mean & & $0.76 a$ & 0.74 & 0.75 & $0.76 a$ & 0.75 & 0.75 & 0.12 & 0.40 & 0.19 & 0.74 \\
\hline & $95 \% \mathrm{Cl}$ & LB & 0.76 & 0.73 & 0.73 & 0.76 & 0.74 & 0.73 & & & & \\
\hline & & UB & 0.76 & 0.75 & 0.76 & 0.76 & 0.77 & 0.76 & & & & \\
\hline \multirow[t]{3}{*}{ Ribs } & Mean & & $0.68 a$ & 0.69 & 0.68 & $0.68 a$ & 0.70 & 0.71 & 0.005 & 0.06 & 0.28 & 0.05 \\
\hline & $95 \% \mathrm{Cl}$ & LB & 0.68 & 0.68 & 0.66 & 0.68 & 0.69 & 0.69 & & & & \\
\hline & & UB & 0.68 & 0.71 & 0.70 & 0.68 & 0.72 & 0.73 & & & & \\
\hline \multirow[t]{3}{*}{ Thoracic } & Mean & & $0.97 a$ & 1.00 & 0.98 & $0.97 a$ & 1.00 & 1.04 & 0.11 & 0.003 & 0.62 & 0.007 \\
\hline & $95 \% \mathrm{Cl}$ & LB & 0.97 & 0.97 & 0.95 & 0.97 & 0.96 & 1.01 & & & & \\
\hline & & UB & 0.97 & 1.03 & 1.01 & 0.97 & 1.03 & 1.08 & & & & \\
\hline \multirow[t]{3}{*}{ Lumbar } & Mean & & $1.05 a$ & 1.05 & 1.05 & $1.05 a$ & 1.09 & 1.09 & 0.69 & 0.03 & 0.18 & 0.05 \\
\hline & $95 \% \mathrm{Cl}$ & LB & 1.05 & 1.03 & 1.02 & 1.05 & 1.06 & 1.06 & & & & \\
\hline & & UB & 1.05 & 1.08 & 1.08 & 1.05 & 1.12 & 1.12 & & & & \\
\hline \multirow[t]{3}{*}{ Pelvis } & Mean & & $1.12 \mathrm{a}$ & 1.20 & 1.21 & $1.12 a$ & 1.20 & 1.22 & 0.04 & 0.73 & 0.62 & 0.38 \\
\hline & $95 \% \mathrm{Cl}$ & LB & 1.12 & 1.18 & 1.20 & 1.12 & 1.18 & 1.21 & & & & \\
\hline & & UB & 1.12 & 1.21 & 1.23 & 1.12 & 1.22 & 1.25 & & & & \\
\hline \multirow[t]{3}{*}{ Legs } & Mean & & $1.20 \mathrm{a}$ & 1.19 & 1.18 & $1.20 a$ & 1.20 & 1.20 & 0.60 & 0.33 & 0.49 & 0.31 \\
\hline & $95 \% \mathrm{Cl}$ & LB & 1.20 & 1.18 & 1.17 & 1.20 & 1.18 & 1.18 & & & & \\
\hline & & UB & 1.20 & 1.20 & 1.21 & 1.20 & 1.22 & 1.21 & & & & \\
\hline
\end{tabular}




\begin{tabular}{|l|l|l|l|l|l|l|l|l|l|l|l|l|}
\hline BMDcore & Mean & & $3.90 \mathrm{a}$ & 3.93 & 3.92 & $3.90 \mathrm{a}$ & 3.99 & 4.07 & 0.23 & 0.0001 & 0.20 & 0.001 \\
\hline & $95 \%$ Cl & LB & 3.90 & 3.88 & 3.87 & 3.90 & 3.93 & 4.04 & & & \\
\hline & & UB & 3.90 & 3.98 & 3.97 & 3.90 & 4.01 & 4.13 & & & \\
\hline
\end{tabular}

Abbreviations: Grp = Group; Diff = Difference; Cl-Confidence Interval; V1 = Visit 1; V1 = Visit 1; V2 = Visit 2; V3 = Visit 3; $\Delta=$ Change score; $L B=$ Lower Bound; UB = Upper Bound; BMD = Bone Mineral Density

100

80

60

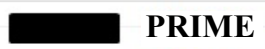

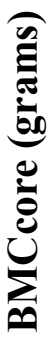

40

$-20$

20

\section{0}

$\mid$

, IIIIIIII

I

$-40$

$-60$

Figure 1a: Individual BMCcore changes after 12 weeks of exercise training.

vis. Change scores (V3-V1) between groups were:(1) Arms: PRIME: $0.030 \mathrm{~g} / \mathrm{cm}^{3}$ [0.070 to 0.054$]$; AT: $-0.004 \mathrm{~g} / \mathrm{cm}^{3}$ [-8.69-2.15], $\mathrm{p}=0.04$, (2) Ribs (PRIME: $0.036 \mathrm{~g} / \mathrm{cm}^{3}[95 \% \mathrm{Cl}: 0.014$ to 0.057$]$; AT: $-0.003 \mathrm{~g}$ [95\% Cl: -0.022 to 0.016 ], $p=0.009$ ); (3) Thoracic Spine (PRIME: $0.071 \mathrm{~g} / \mathrm{cm}^{3}$ [95\% Cl: 0.039 to 0.103 ]; AT: $0.009 \mathrm{~g} / \mathrm{cm}^{3}$ [95\% Cl: -0.018 to 0.037 ], $p=0.0001$ ), Lumbar spine (PRIME: $0.046 \mathrm{~g} / \mathrm{cm}^{3}$ [95\% Cl: 0.013 to 0.079]; AT: $0.002 \mathrm{~g} / \mathrm{cm}^{3}$ [95\% Cl: -0.027 to 0.030 ], $\mathrm{p}$ $=0.82$ ), Pelvis (PRIME: $0.025 \mathrm{~g} / \mathrm{cm}^{3}$ [95\% Cl: 0.006 to 0.043]; AT: $0.014 \mathrm{~g} / \mathrm{cm}^{3}$ [95\% Cl: -0.003 to 0.030 ], $\mathrm{p}$ $=0.24$ ), Legs (PRIME: $-0.002 \mathrm{~g} / \mathrm{cm}^{3}[95 \% \mathrm{Cl}:-0.017$ to 0.014]; AT: $-0.018 \mathrm{~g} / \mathrm{cm}^{3}$ [95\% Cl: -0.031 to -0.004 ], $p$ $=0.23$ ), and for BMDcore (PRIME: $0.206 \mathrm{~g} / \mathrm{cm}^{3}[95 \%$ $\mathrm{Cl}: 0.140$ to 0.271 ]; $\mathrm{AT}: 0.001 \mathrm{~g} / \mathrm{cm}^{3}$ [95\% $\mathrm{Cl}:-0.058$ to 0.058], $p=0.0001$ ).

Individual changes in BMCcore and BMDcore are depicted in Figure $1 \mathrm{a}$ and Figure $1 \mathrm{~b}$. Those randomized to PRIME had a greater likelihood of improvement in BMCcore and BMDcore after Phase II, with $70 \%$ of PRIME versus $25 \%$ of AT (Figure 1 a) and $78 \%$ of PRIME versus $55 \%$ of AT (Figure $1 \mathrm{~b}$ ) demonstrating improvements, respectively.

\section{Discussion}

The unique contributions of this study are 2-fold: (1) Participants whom initiated training with PRIME experienced greater improvements in BMC and BMD, and (2) Starting an exercise program for older adults at risk of losing independence, using a low intensity systemic, yet moderate to high intensity localized exercise stimulus, represent a novel approach which may be beneficial to those with cardiorespiratory or other systemic limitations.

\section{Body composition}

Both groups decreased percent body fat. The $\sim 1 \%$ decrease in percent fat is similar to those observed in the original study from Pollock's laboratory, comparing AT and RT responses in 70 to 79-year-olds [23]. Similarly changes in fat mass were greater in those who performed AT only [23]. Importantly, both groups increased SMI. These changes are relevant in that SMI is used to identify those considered sarcopenic [22,24]. The PRIME study was not powered to address this issue directly, so we remain conservative, only to suggest exercise training serves as a countermeasure to advancing sarco- 
0.6

0.5

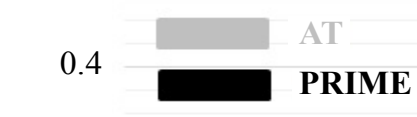

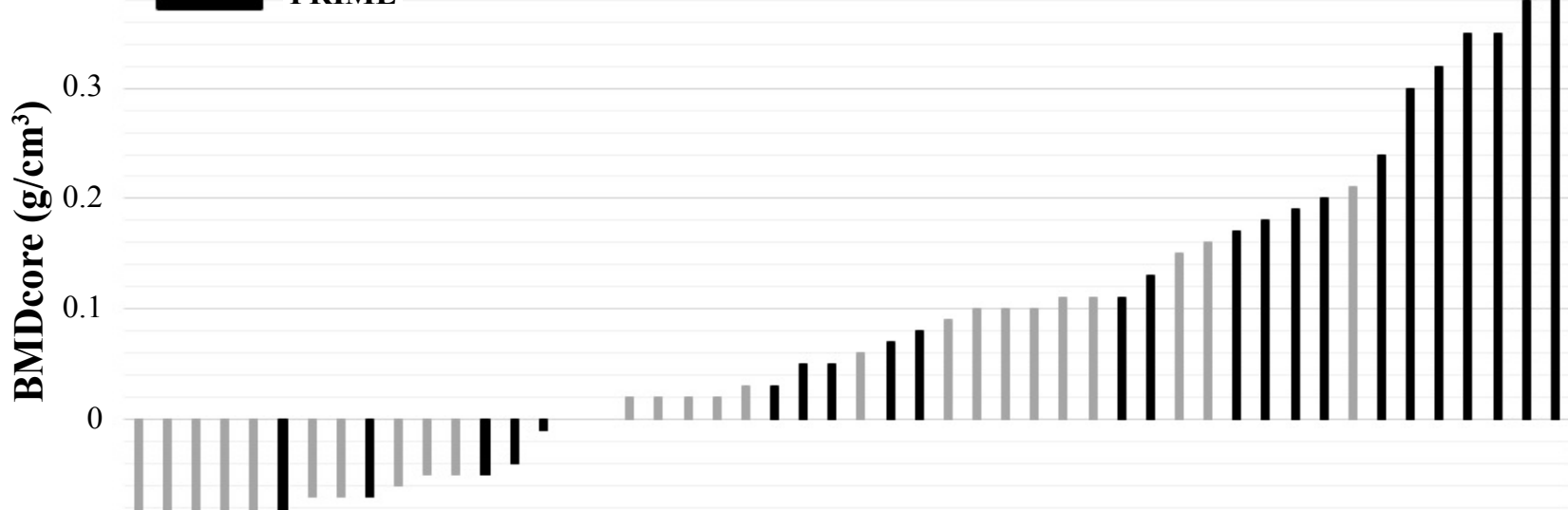

$-0.1$

$-0.3$

Figure 1b: Individual BMDcore changes after 12 weeks of exercise training.

penia. Future studies should address the value of SMI changes in regard to maintaining independence. The small changes in FFM may be due to neural adaptations, rather than hypertrophy [25].

\section{Bone mineral content and density}

A unique finding within this report is the observed increases in BMC and BMD, particularly in the PRIME group. The findings $B M C$ and $B M D$ increased to a greater extent in PRIME versus AT suggests the differential loading conditions in Phase I were important in the overall training response. The confidence in the observed findings may be explained as follows: (1) The number of targeted exercises used, in PRIME, during PHASE I; (2) The progression in the mechanical loading conditions within Phase I, in the targeted areas; (3) The similarities in the responses between PRIME and AT in the pelvic area; and (4) The individual responses in BMC and BMD in those randomized to PRIME or AT. In regard to the first point, six of 8 PRIME exercises aimed to target core strength, involving many of the areas and sites measured with the DXA. The delivery of these exercises was such that the load and cycle number were high, as shown to be required [26]. Moreover, the exercises were developed to ensure sufficient overlap on major muscle groups and joints. Thus, most muscle groups, in PRIME, received multiple loading conditions, within the same session, potentially optimizing the stimulus for adaptation. In addition, those involved in PRIME had an increase in volume/load of $\sim 14 \%$ from week 1 \& 2 to week 3 \& 4 , in Phase I. Consequently, the specific sites received considerable and progressive stimulation. Arguably, the AT group did not receive such a consistent stimulus, during Phase I, except for the Pelvic area, due to its involvement in cycling and walking. Finally, PRIME participants responded to the training period in a more favorable manner, with 16 and 18 out of 23 PRIME participants reporting an increase in BMCcore and BMDcore vs. 7 and 15 out of 27 of AT participants, respectively.

The observed increases in this study, seen within 3 months, are of similar magnitude to studies with training programs over 6 months. For example, a recent systematic review examining BMD changes in older adults following exercise training showed the earliest evidence for change around 4 months [26]. In fact, the first study to report a change in BMC of $\sim 5 \%$ after 6 months of walking at an intensity of $70-90 \% \mathrm{VO}_{2}$ max was performed in post-menopausal women [27]. However, most studies that have examined the effects of AT on BMC and BMD reported no increase unless high mechanical loads are generated at the bone [26]. RT provides more consistent evidence of increased BMC and BMD in older populations, after 6 months. The gains typically involve only the areas that receive the mechanical load [26].

The greater improvements in BMC and BMD, in PRIME, evident after 12 weeks are, intriguing. During Phase II of the intervention both groups trained at similar intensities and progressed equally (Table 3 ): We can only speculate the initial training period provided a su- 
perior signal for adaptation that subsequently carried through phase II. It is premature to suggest underlying mechanisms for the changes, but evidence indicates the skeletal muscle secretome is sensitive to mechanical contractions [28]. The subsequent effects of muscle contractions may produce specific myokines involved in triggering a number of pathways contributing to end-organ responses, including bone [29].

\section{Clinical relevance}

According to Wolfe: "Elderly individuals particularly women, are often too weak to perform the intensity of exercise necessary to induce the same magnitude of physiologic adaptations that occur in younger" [30]. In fact, many individuals are not able to perform at a high enough intensity of exercise to induce adaptations because of systemic limitations. The current study offers a novel approach that allows for significant changes in physiologic and functional phenotypes, if training is initiated with a low-mass, high-repetition/volume mechanical loading scheme under a relatively low systemic strain, and followed by training guidelines as recommended by American College of Sports Medicine/American Heart Association guidelines) [19].

\section{Study limitations}

Exercise guidelines for older individuals include recommendations for a well-rounded training program applied in the context of the participant's needs, goals, and baseline functional abilities, and with a gradual progression in duration and intensity of effort for cardio-respiratory, muscular strength and endurance, and flexibility components $[13,18,19]$. The recommendations provide little insight how to incorporate principles of specificity, overload and progression into the regimen in order to optimize functional benefits. Implementation usually starts with a moderate intensity systemic exercise stimulus, with a gradual increase in time and intensity as tolerated and inclusion of RT later in the program. This study is thus delimited in our interpretation of the order which is common practice, i.e. AT first, followed by gradual increase of other training components. We do not know how individuals would compare if PRIME were to be matched with RT (or any other order of presentation).

The selection of 4 weeks of PRIME is based on previous studies which focused on the effects of a local training stimulus on vasodilatory function [31,32]. PRIME has not been extended beyond 4 weeks, to determine if the responses differ. However, within that argument it is perhaps key to focus on the consistent improvements observed in BMC and BMD, with PRIME, in this vulnerable population. Not only are the improvements in functional ability, relevant, as reported, but the present study could potentially support the use of PRIME as an early intervention for those who are osteopenic.

\section{Conclusion}

Exercise training for older adults at risk of losing independence results in beneficial changes in body composition. Importantly, this study highlights the feasibility and superiority of initiating exercise training using a low intensity systemic, yet moderate to high intensity localized exercise stimulus, as it relates to bone health. As such these data support further research to examine the need for a shift in the paradigm of initiating exercise training in the elderly from the traditional moderate to high intensity systemic exercise stimulus, toward the use of moderate to high intensity localized exercise.

\section{Competing Interests}

The authors declare that they have no competing interests.

\section{Authors' Contributions}

MAW and JDA conceived and designed the study, analyzed data, interpreted the findings and contributed to writing the manuscript; MCS executed the exercise programs, analyzed data, interpreted the findings, and contributed to writing the manuscript; NMJ and DPC helped in the design of the study, interpreted the findings and contributed to writing the manuscript. CPE, TSC, ER, WEK, assisted in interpreting the findings and contributed to writing the manuscript. All authors have read and approved the final version of the manuscript, and agree with the order of the presentation of authors.

This work was supported by the National Institutes of Aging (grant no. 1RC1AG035822, 2009).

\section{References}

1. Fleg JL, Morrell CH, Bos AG, Brant LJ, Talbot LA, et al. (2005) Accelerated longitudinal decline of aerobic capacity in healthy older adults. Circulation 2: 674-682.

2. Wilson PW, Kannel WB (2002) Obesity, diabetes, and risk of cardiovascular disease in the elderly. Am J Geriatr Cardiol 11: 119-123.

3. Hunter GR, Gower BA, Kane BL (2010) Age Related Shift in Visceral Fat. Int J Body Compos Res 8: 103-108.

4. Baxter-Jones $A D$, Faulkner RA, Forwood MR, Mirwald RL, Bailey DA (2011) Bone mineral accrual from 8 to 30 years of age: an estimation of peak bone mass. J Bone Miner Res 26: $1729-1739$.

5. Wilsgaard T, Emaus N, Ahmed LA, Grimnes G, Joakimsen RM, et al. (2009) Lifestyle impact on lifetime bone loss in women and men: the Tromsø Study. Am J Epidemiol 169: 877-886.

6. Eckel RH, Grundy SM, Zimmet PZ (2005) The metabolic syndrome. Lancet 365: 1415-1428.

7. Frayn KN (2000) Visceral fat and insulin resistance- causative or correlative? Br J Nutr 83: 71-77.

8. Evans WJ, Campbell WW (1993) Sarcopenia and age-related changes in body composition and functional capacity. $J$ Nutr 123: 465-468.

9. Nguyen TV, Kelly PJ, Sambrook PN, Gilbert C, Pocock NA, 
et al. (1994) Lifestyle factors and bone density in the elderly: implications for osteoporosis prevention. J Bone Miner Res 9: 1339-1346.

10. Fried LP, Tangen CM, Walston J, Newman AB, Hirsch C, et al. (2001) Frailty in older adults: evidence for a phenotype. J Gerontol A Biol Sci Med Sci 56: 146-156.

11. Booth FW, Roberts CK, Thyfault JP, Ruegsegger GN, Toedebusch RG (2017) Role of Inactivity in Chronic Diseases: Evolutionary Insight and Pathophysiological Mechanisms. Physiol Rev 97: 1351-1402.

12. National Institutes of Health, Organization WH. Global Health and Aging.

13. American College of Sports Medicine, Chodzko-Zajko WJ, Proctor DN, Fiatarone Singh MA, Minson CT, et al. (2009) American College of Sports Medicine position stand. Exercise and physical activity for older adults. Med Sci Sports Exerc 41: 1510-1530.

14. Allen JD, Vanbruggen MD, Johannsen NM, Robbins JL, Credeur DP, et al. (2018) PRIME: A Novel Low-Mass, High-Repetition Approach to Improve Function in Older Adults. Med Sci Sports Exerc 50: 1005-1014.

15. Paterson DH, Warburton DE (2010) Physical activity and functional limitations in older adults: a systematic review related to Canada's Physical Activity Guidelines. Int J Behav Nutr Phys Act 7: 38.

16. Cress ME, Meyer M (2003) Maximal voluntary and functional performance levels needed for independence in adults aged 65 to 97 years. Phys Ther 83: 37-48.

17. Allen JD, Robbins JL, VanBruggen MD, Credeur DP, Johannsen NM, et al. (2013) Unlocking the barriers to improved functional capacity in the elderly: rationale and design for the "Fit for Life trial." Contemp Clin Trials 36: 266-275.

18. Garber CE, Blissmer B, Deschenes MR, Franklin BA, Lamonte MJ, et al. (2011) Quantity and quality of exercise for developing and maintaining cardiorespiratory, musculoskeletal, and neuromotor fitness in apparently healthy adults: guidance for prescribing exercise. Med Sci Sports Exerc 43: 1334-1359.

19. Nelson ME, Rejeski WJ, Blair SN, Duncan PW, Judge JO, et al. (2007) Physical activity and public health in older adults. Recommendation from the American College of Sports Medicine and the American Heart Association. Circulation 116: 1094-1105.

20. Riebe D, Ehrman JK, Liguori G, Magal M, American College of Sports Medicine (2017) ACSM Guidelines for Exercise
Testing and Prescription. (10 $10^{\text {th }}$ edn), Philadelphia: Wolters Kluwer, 192-193.

21. Lohman M, Tallroth K, Kettunen JA, Marttinen MT (2009) Reproducibility of dual-energy $\mathrm{x}$-ray absorptiometry total and regional body composition measurements using different scanning positions and definitions of regions. Metabolism 58: 1663-1668.

22. Cruz-Jentoft AJ, Baeyens JP, Bauer JM, Boirie Y, Cederholm T, et al. (2010) Sarcopenia: European consensus on definition and diagnosis: Report of the European Working Group on Sarcopenia in Older People. Age Ageing 39: 412423.

23. Hersey WC, Graves JE, Pollock ML, Gingerich R, Shireman RB, et al. (1994) Endurance exercise training improves body composition and plasma insulin responses in 70- to 79-year-old men and women. Metabolism 43: 847-854.

24. Locquet $M$, Beaudart $C$, Bruyère $O$, Kanis JA, Delandsheere L, et al. (2018) Bone health assessment in older people with or without muscle health impairment. Osteoporos Int 29: 1057-1067.

25. Moritani T, deVries HA (1980) Potential for gross muscle hypertrophy in older men. J Gerontol 35: 672-682.

26. Gómez-Cabello A, Ara I, González-Agüero A, Casajús JA, Vicente-Rodríguez G (2012) Effects of training on bone mass in older adults: a systematic review. Sports Med 42: 301-325.

27. Dalsky GP, Stocke KS, Ehsani AA, Slatopolsky E, Lee WC, et al. (1988) Weight-bearing exercise training and lumbar bone mineral content in postmenopausal women. Ann Intern Med 108: 824-828.

28. Hamrick MW (2012) The skeletal muscle secretome: an emerging player in muscle-bone crosstalk. Bonekey Rep 1: 60 .

29. Wolfe RR (2006) The underappreciated role of muscle in health and disease. Am J Clin Nutr 84: 475-482.

30. Pedersen BK (2013) Muscle as a secretory organ. Compr Physiol 3: 1337-1362.

31. Allen JD, Geaghan JP, Greenway F, Welsch MA (2003) Time-Course of Vascular Adaptations following Localized Short-Term Exercise Training. Med Sci Sports Exerc 35: 847-853.

32. Dobrosielski DA, Greenway F, Welsh D, Jazwinski SM, Welsch MA, et al. (2009) Modification of vascular function in elderly men following handgrip exercise training. Med Sci Sports Exerc 41: 1429-1435. 